\title{
Note on Romanization and Abbreviations
}

Tibetan written and spoken forms diverge considerably, the written form containing consonant clusters that are not pronounced: e.g., the Tibet name Chagö Tomden is actually spelled (romanized) bya rgod stobs ldan. Throughout this book, the spoken (phonetic) pronunciation is used for Tibetan proper names and titles, with the correct spellings given in romanization in the "Glossary of Correct Tibetan Spellings" at the end of the book. However, in some cases, Tibetan terms or phrases mentioned in the text are accompanied by the correct Tibetan spelling. These are placed in brackets and preceded by "tib.": for example, "the Spark Association [tib. me stag tshogs pa]." Since the Tibetan language does not distinguish between capital and lowercase letters, all correct Tibetan spellings are cited with lowercase letters.

Chinese names and terms are cited in the standard pinyin system used in the People's Republic of China, with the exception of the established older spelling of Chiang Kaishek. Chinese pinyin terms or phrases are introduced by "ch.": for example, "the Spark Association [tib. me stag tshogs pa; ch. xing huo she]."

The following abbreviations are used in the text:

CCP Chinese Communist Party

GMD Guomindang Party/Government of Chiang Kaishek (also called the Chinese Nationalist Party/Chinese Nationalist Government) 
NPC National People's Congress

PLA People's Liberation Army

PRC People's Republic of China

TAR Tibet Autonomous Region 